\title{
Contrasting Thermoelectric Transport Behaviors of $p$-Type PbS Caused by Doping Alkali Metals (Li and Na)
}

\author{
Zhenghao Hou, ${ }^{1}$ Dongyang Wang, ${ }^{1}$ Jinfeng Wang, ${ }^{2}$ Guangtao Wang, ${ }^{2}$ Zhiwei Huang, \\ and Li-Dong Zhao ${ }^{1}{ }^{1}$ \\ ${ }^{1}$ School of Materials Science and Engineering, Beihang University, Beijing 100191, China \\ ${ }^{2}$ School of Physics, Henan Normal University, Xinxiang 453007, China \\ Correspondence should be addressed to Zhiwei Huang; zwhuang@buaa.edu.cn and Li-Dong Zhao; zhaolidong@buaa.edu.cn
}

Received 26 September 2020; Accepted 25 October 2020; Published 3 December 2020

Copyright ( 2020 Zhenghao Hou et al. Exclusive Licensee Science and Technology Review Publishing House. Distributed under a Creative Commons Attribution License (CC BY 4.0).

\begin{abstract}
$\mathrm{PbS}$ is a latent substitute of PbTe thermoelectric materials, which is on account of its superiority in low cost and earth abundance. Here, the thermoelectric transport properties of $p$-type $\mathrm{PbS}$ by doping alkali metals $(\mathrm{Na}$ and $\mathrm{Li}$ ) are investigated and it is verified that $\mathrm{Li}$ is a more effective dopant than $\mathrm{Na}$. By introducing $\mathrm{Li}$, the electrical and thermal transport properties were optimized collectively. The electrical transport properties were boosted remarkably via adjusting carrier concentration, and the maximum power factor $\left(\mathrm{PF}_{\max }\right)$ of $\sim 11.5 \mu \mathrm{W} / \mathrm{cmK}^{2}$ and average power factor $\left(\mathrm{PF}_{\text {ave }}\right) \sim 9.9 \mu \mathrm{W} / \mathrm{cmK}^{2}$ between 423 and $730 \mathrm{~K}$ in $\mathrm{Pb}_{0.99} \mathrm{Li}_{0.01} \mathrm{~S}$ were achieved, which are much higher than those $\left(\sim 9.5\right.$ and $\left.\sim 7.7 \mu \mathrm{W} / \mathrm{cmK}^{2}\right)$ of $\mathrm{Pb}_{0.99} \mathrm{Na}_{0.01} \mathrm{~S}$. Doping $\mathrm{Li}$ and $\mathrm{Na}$ can weaken the lattice thermal conductivity effectively. Combining the enlarged PF with suppressed total thermal conductivity, a maximum $\mathrm{ZT} \sim 0.5$ at $730 \mathrm{~K}$ and a large average $\mathrm{ZT} \sim 0.4$ at $423-730 \mathrm{~K}$ were obtained in $p$-type $\mathrm{Pb}_{0.99} \mathrm{Li}_{0.01} \mathrm{~S}$, which are higher than $\sim 0.4$ and $\sim 0.3$ in $p$-type $\mathrm{Pb}_{0.99} \mathrm{Na}_{0.01} \mathrm{~S}$, respectively.
\end{abstract}

\section{Introduction}

The search for reliable and environmentally friendly new energy has attracted worldwide attention because of the shortage of fossil energy. A thermoelectric device is capable of transforming heat into electric energy immediately, which has shown great prospect in clean energy field [1-5]. The thermoelectric device efficiency is positively associated with the dimensionless figure of merit [6-9], $\mathrm{ZT}=S^{2} \sigma T / \kappa_{\text {tot }}$, where $T$ represents absolute temperature, $S$ expresses the Seebeck coefficient, $\sigma$ denotes electrical conductivity, and $\kappa_{\text {tot }}$ represents total thermal conductivity comprising electronic $\left(\kappa_{\text {ele }}\right)$ and lattice $\left(\kappa_{\text {lat }}\right)$ contributions $[2,10,11]$.

Lead telluride- $(\mathrm{PbTe}-)$ based materials, as a kind of medium-temperature operating materials, have attracted extensive research interests on account of outstanding thermoelectric performance [12-14]. However, considering the high costs and low earth abundance of the Te element, the thermoelectric materials with rich resources should be developed. To date, one research hotpot in this field is to find an alternative material to substitute $\mathrm{PbTe}$ which possesses prominent thermoelectric properties [14-16]. As a similar alternative of $\mathrm{PbTe}, \mathrm{PbS}$ possesses a $\mathrm{NaCl}$ structure and an alike band structure. Nevertheless, the poor electrical properties and large lattice thermal conductivity historically make $\mathrm{PbS}$ become an inferior thermoelectric material [11]. Aimed at solving the shortcomings of $\mathrm{PbS}$, the approaches including carrier concentration optimization [17], band manipulation [18], and microstructure engineering [19-22] have been proved as effective strategies to manipulate electrical properties and thermal conductivity; the achievements realized through the above strategies well elucidate the potential performance of $\mathrm{PbS}$.

Usually, doping is a powerful tactic to enhance ZT. Doping is essential in adjusting carrier concentration, and it is the prerequisite to gain a high ZT as all of those thermoelectric properties are interlinked by carrier concentration. On the assumption that the scattering or band structure is not modified obviously by a dopant, the Seebeck coefficient and electrical conductivity of degenerated semiconductor with a single parabolic band can be given using Equations (1) and (2) [23, 24]. 


$$
\begin{aligned}
& S=\frac{8 \pi^{2} k_{\mathrm{B}}^{2}}{3 e h^{2}} m^{*} T\left(\frac{\pi}{3 n}\right)^{2 / 3}, \\
& \sigma=n e \mu_{n},
\end{aligned}
$$

where $k_{\mathrm{B}}$ displays the Boltzmann constant, $e$ shows the electron charge, $h$ denotes the Planck constant, $m^{*}$ expresses effective mass, $n$ is the carrier concentration, and $\mu_{n}$ represents the carrier mobility. Apparently, $S$ and $\sigma$ are in an inversely proportional relationship. Therefore, adjusting carrier concentration through balancing the relationship between $S$ and $\sigma$ is an important method to boost power factors. Doping with different elements may induce diverse impact on carrier concentration optimization and band structure manipulation. For example, $p$-type $\mathrm{Na}$-doped $\mathrm{PbS}$ with $\mathrm{CdS}$ as second phases attains a large $\mathrm{ZT} \sim 1.3$ at $923 \mathrm{~K}$ owing to extensive phonon scattering by nanophase precipitates and better electrical transport [25]; the ZT of p-type Tl-doped $\mathrm{PbTe}$ reaches $\sim 1.5$ at $773 \mathrm{~K}$ due to greatly enhanced Seebeck coefficients by deformation of electronic density of states [17]. It is meaningful to speculate the impacts by doping other alkali metals on thermoelectric performance in $\mathrm{PbS}$.

In this article, we focused on $\mathrm{PbS}$, which contains highly earth-abundant elements and owns higher melting point compared to $\mathrm{PbTe}$. The thermoelectric properties in $\mathrm{PbS}$ doped by $\mathrm{Li}$ and $\mathrm{Na}$ were investigated systematically. The consequences reveal that the electrical and thermal properties were optimized synchronously through alkali metal doping. The electrical properties were improved through adjusting carrier concentration, and the $\mathrm{PF}_{\max }$ of $\mathrm{Pb}_{0.99} \mathrm{Li}_{0.01} \mathrm{~S}$ reached $\sim 11.5 \mu \mathrm{W} / \mathrm{cmK}^{2}$, which is far greater than $\sim 9.5 \mu \mathrm{W} / \mathrm{cmK}^{2}$ in $\mathrm{Pb}_{0.99} \mathrm{Na}_{0.01} \mathrm{~S}$. Both $\mathrm{Li}$ and $\mathrm{Na}$ can bring down the $\kappa_{\text {lat }}$ because of point defects in PbS matrix. $\mathrm{Li}$ was more effective than $\mathrm{Na}$ in reducing $\kappa_{\text {lat }}$ on account of larger mass and strain field fluctuations. Integrating enhanced PF and reduced $\kappa_{\text {tot }}$, a higher $\mathrm{ZT}$ value $\sim 0.5$ at $730 \mathrm{~K}$ and average ZT $\sim 0.4$ at $423-730 \mathrm{~K}$ can be reached in $\mathrm{Pb}_{0.99} \mathrm{Li}_{0.01} \mathrm{~S}$, which are higher than $\sim 0.4$ and $\sim 0.3$ in $p$ type $\mathrm{Pb}_{0.99} \mathrm{Na}_{0.01} \mathrm{~S}$, respectively, indicating that $\mathrm{Li}$ doping can improve thermoelectric performance of $\mathrm{PbS}$ more effectively than $\mathrm{Na}$ doping.

\section{Experimental Section}

2.1. Preparation Method. High-purity chemicals of $\mathrm{Pb}$ particle (99.99\%), S (99.99\%), Na (99.99\%), and Li (99.99\%) were weighed and loaded into carbon-coated quartz ampules under a $\mathrm{N}_{2}$-filled glove box. The ampules of the chemicals were evacuated under vacuum and flame-sealed. The pure chemicals were gradually warmed up to $723 \mathrm{~K}$ in $12 \mathrm{~h}$, elevated to $1423 \mathrm{~K}$ in $7 \mathrm{~h}$ before keeping stable at $1423 \mathrm{~K}$ for $6 \mathrm{~h}$, and finally naturally cooled to indoor temperature. The prepared specimens were pulverized and filtered with 400mesh sieves for sintering through spark plasma sintering (SPS-211LX) using a pressure of $50 \mathrm{MPa}$ at $923 \mathrm{~K}$ for $10 \mathrm{~min}$.

2.2. Thermoelectric Properties. The acquired cylinder bulk materials were incised for measuring relevant thermoelectric properties. The CTA system was applied to measure electrical parameters $(S$ and $\sigma)$ at $300-730 \mathrm{~K}$ under He gas, and the samples were polished in a rectangular shape of $10 \mathrm{~mm} \times$ $3 \mathrm{~mm} \times 3 \mathrm{~mm}$. The surfaces of measured samples were sprayed with thin-layer $\mathrm{BN}$, which can inhibit volatilization and protect instrument [26]. The cylindrical disks with thickness of $1 \mathrm{~mm}$ and diameter of $6 \mathrm{~mm}$ were used to measure the thermal diffusivity $(D)$. The thermal conductivity is computed through $\kappa_{\text {tot }}=D C_{\mathrm{p}} \rho$, and the thermal diffusivity was characterized using a Netzsch LFA457 instrument with a laser flash method [27]. A thin graphite film on the surface of samples was utilized to cut down errors of emissivity for testing $D$. The density $(\rho)$ was obtained based on mass and volume. All the densities of samples are around $7.2 \mathrm{~g} / \mathrm{cm}^{3}$. The heat capacity $\left(C_{\mathrm{p}}\right)$ was computed using the Debye model [28].

2.3. X-Ray Diffraction. The phase structure was investigated using an X-ray diffraction technique with D/MAX2200pc system with $\mathrm{CuK} \alpha$ at $2 \theta=20-80^{\circ}$ (Rigaku, Japan, $40 \mathrm{kV}$, $40 \mathrm{~mA}$ ). The scanning speed and step size of the XRD measurement are $6^{\circ} \mathrm{min}^{-1}$ and $0.02^{\circ}$, respectively.

2.4. Theoretical Calculations. The density functional theory (DFT) calculations were acquired through a projectoraugmented wave (PAW) strategy $[29,30]$ with the Vienna $\mathrm{Ab}$ initio Simulation Package (VASP) [31]. The PerdewBurke-Ernzerhof (PBE) exchange-correlation functional was used to model crystal and electronic structure. The used kinetic cutoff energy of plane waves is $500 \mathrm{eV}$. A $3 \times 3 \times 3$ supercell $\left(\mathrm{Pb}_{27} \mathrm{~S}_{27}\right)$ was constructed to evaluate the defect formation energy of Li- $\left(\mathrm{Pb}_{26} \mathrm{LiS}_{27}\right)$ and $\mathrm{Na}-\left(\mathrm{Pb}_{26} \mathrm{NaS}_{27}\right)$ doped systems. The internal coordinates of all atoms are entirely relaxed while the maximum residual ionic force is lower than $0.01 \mathrm{eV}^{-1}$, and the total energy difference approaches $10^{-6} \mathrm{eV}$.

The formation energy of the defect $Q(Q=\mathrm{Na}, \mathrm{Li})$ in charge $q$ is calculated by $[32,33]$

$$
\begin{aligned}
\Delta H^{\mathrm{f}}\left(\mathrm{PbS}, \mathrm{Q}^{q}\right)= & E\left(\mathrm{PbS}, Q^{q}\right)-E(\mathrm{PbS})+\sum_{i} n_{i}\left(E_{i}+\mu_{i}\right) \\
& +q\left(E_{\mathrm{F}}+E_{\mathrm{V}}+\Delta V\right),
\end{aligned}
$$

where $E\left(\mathrm{PbS}, \mathrm{Q}^{q}\right)$ and $E(\mathrm{PbS})$ refer to the total energy of defect $\alpha$ contained and undoped $\mathrm{PbS}$ in supercells with the same dimension, separately. $\mu_{i}, E_{i}$, and $n_{i}$ are the chemical potential, average energy of element in its most stable crystal structure, and the number of the atom $i$ added to $\left(n_{i}<0\right)$ or taken from $\left(n_{i}>0\right)$ the host, respectively. $E_{\mathrm{F}}$ presents the Fermi level relative to energy location of valence band maximum $\left(E_{\mathrm{v}}\right)$, which changes between 0 and band gap in $\mathrm{PbS}$. The correction term $\Delta V$ is adopted to arrange the reference potential between the defect-containing and pure supercells with the same size [34]. All characteristic values are recombined to the $1 \mathrm{~s}$ core level of the atom farthest from the defect $[32,35]$.

The formation energy depends on the chemical potential of each element, which is related to the off-stoichiometric 
degree ( $\mathrm{Pb}$ - or S-rich condition). The different offstoichiometric degrees will result in different chemical potential and formation energy. The upper and lower boundary chemical potential $\left(\mu_{i}\right)$ is determined by the off-stoichiometric degree and the stability against precipitation of elemental $\mathrm{Pb}, \mathrm{S}, \mathrm{Li}$, and $\mathrm{Na}$ :

$$
\mu_{\mathrm{Pb}}, \mu_{\mathrm{S}}, \mu_{\mathrm{Li}}, \mu_{\mathrm{Na}} \leq 0
$$

The host compounds are obtained from the sum of the chemical potentials of $\mathrm{Pb}$ and $\mathrm{S}$ :

$$
\mu_{\mathrm{Pb}}+\mu_{\mathrm{S}}=\Delta H^{\mathrm{f}}(\mathrm{PbS})
$$

where $\Delta H^{\mathrm{f}}(\mathrm{PbS})$ is the formation energy of $\mathrm{PbS}$ in a rocksalt structure.

The second phase of $\mathrm{Na}_{2} \mathrm{~S}, \mathrm{Li}_{2} \mathrm{~S}$, and $\mathrm{PbS}_{2}$ should be avoided, and the corresponding formation energy should be larger than the sum of elemental chemical potential:

$$
\begin{gathered}
2 \mu_{\mathrm{Na}}+\mu_{\mathrm{S}}<\Delta H^{\mathrm{f}}\left(\mathrm{Na}_{2} \mathrm{~S}\right), \\
2 \mu_{\mathrm{Li}}+\mu_{\mathrm{S}}<\Delta H^{\mathrm{f}}\left(\mathrm{Li}_{2} \mathrm{~S}\right), \\
\mu_{\mathrm{Pb}}+2 \mu_{\mathrm{S}}<\Delta H^{\mathrm{f}}\left(\mathrm{PbS}_{2}\right) .
\end{gathered}
$$

\section{Results and Discussion}

Figure 1 demonstrates the detailed information of XRD results. All specimens possess a single phase of cubic $\mathrm{PbS}$. The data peak transfers to low angle range as the $\mathrm{Li}$ and $\mathrm{Na}$ content was added, which indicates that $\mathrm{Li}$ and $\mathrm{Na}$ are doped into $\mathrm{PbS}$ lattice.

Figure 2 depicts electrical properties in $\mathrm{PbS}$ with $\mathrm{Li}$ and $\mathrm{Na}$ doping. It can be clearly observed from Figures 2(a) and 2(b) that the $\sigma$ falls off when temperature rises, except for low doping samples of $\mathrm{Pb}_{1-x} \mathrm{Na}_{x} \mathrm{~S}(x=0.005$ and 0.0075$)$.

For Li-doped samples, the $\sigma$ possesses a tendency to increase first and then decrease with the stoichiometry of $\mathrm{Li}$ increasing and reaches to its maximum $777 \mathrm{~S} / \mathrm{cm}$ in $\mathrm{Pb}_{0.995} \mathrm{Li}_{0.005} \mathrm{~S}$, as shown in Figure 2(a). However, the $\mathrm{Na}$ doping presents different results. As presented in Figure 2(b), the $\sigma$ has an increased trend with increasing of $\mathrm{Na}$ content, and the maximum $\sigma$ of $1274 \mathrm{~S} / \mathrm{cm}$ can be realized in $\mathrm{Pb}_{0.98} \mathrm{Na}_{0.02} \mathrm{~S}$. The $\sigma$ is positively correlated with $n_{\mathrm{H}}$ and $\mu_{n}$ from Equation (2), which are determined by the solid solubility and the different scattering mechanisms, respectively. The continued increase in $\sigma$ of $\mathrm{Pb}_{1-x} \mathrm{Na}_{x} \mathrm{~S}$ is mainly due to the fact that the higher solubility of $\mathrm{Na}$ than $\mathrm{Li}$ was caused by better ion radius matching $\left(r_{\mathrm{Li}}{ }^{+}=0.76 \AA, r_{\mathrm{Na}}{ }^{+}=1.02 \AA, r_{\mathrm{Pb}}{ }^{2+}=\right.$ $1.26 \AA$ ).

As displayed in Figures 2(c) and 2(d), different from the undoped $\mathrm{PbS}$, the Seebeck coefficients $(S)$ for all doped samples are positive, indicating that $\mathrm{Li}$ and $\mathrm{Na}$ are effective $p$-type dopants in PbS. For Li-doped samples, the $S$ present the trend of first decreasing and then increasing with an increasing $\mathrm{Li}$ content. For Na-doped samples, the trend is reversed that the $S$ increase first and then decrease with an increasing $\mathrm{Na}$ content. These diametrically opposite trends reflect the con-

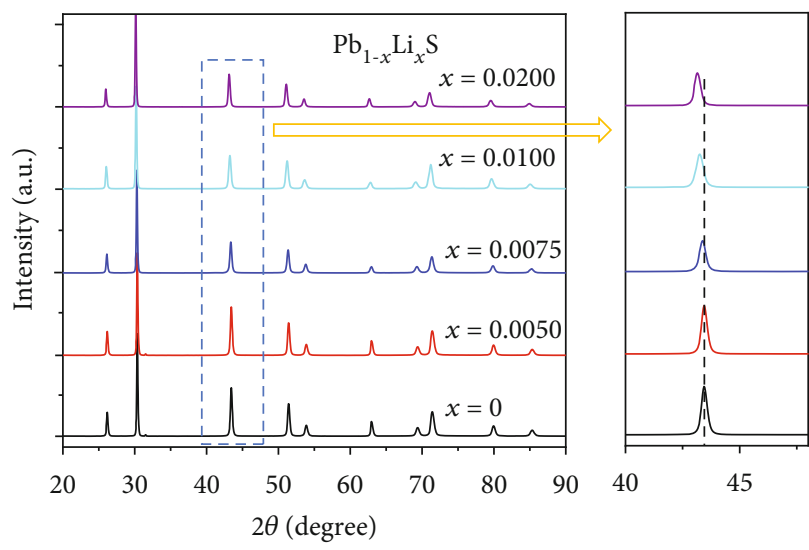

(a)

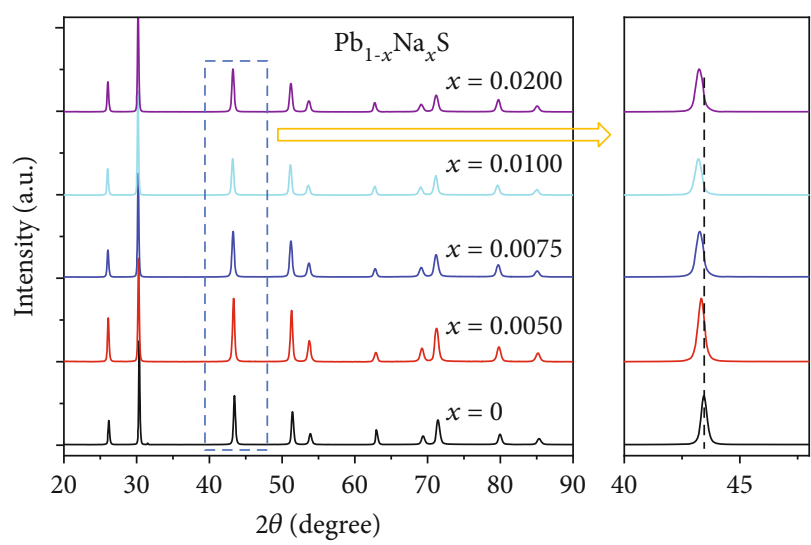

(b)

FIgURe 1: Powder XRD patterns of (a) $\mathrm{Pb}_{1-x} \mathrm{Li}_{x} \mathrm{~S}$ and (b) $\mathrm{Pb}_{1-x} \mathrm{Na}_{x} \mathrm{~S}$.

trary change of carrier concentration $\left(n_{\mathrm{H}}\right)$ in those materials since the $S$ are negatively correlated with $n_{\mathrm{H}}$.

To evaluate the doping efficiency of $\mathrm{Li}$ and $\mathrm{Na}$ in $\mathrm{PbS}$, the formation energy of potential defect was calculated and shown in Figures 3(a) and 3(b). The lower formation energy of $\mathrm{Na}_{\mathrm{Pb}}$ indicates the spontaneous formation of $\mathrm{Na}_{\mathrm{Pb}}$ in any conditions, which is even lower than that in $\mathrm{V}_{\mathrm{Pb}}$. However, the $\mathrm{Li}_{\mathrm{Pb}}$ has higher formation energy under $\mathrm{Pb}$ - and $\mathrm{S}$ - rich situations. In an equilibrium theory, the defect concentration can be evaluated by the formation energy $\Delta H$, expressed as $n_{i}=N_{i} \times e^{(-(\Delta H / k T))}$ [36]. Thus, the larger formation energy of Li leads to a lower $n_{\mathrm{H}}$ and a larger $S$ (Figure 2(c)).

As presented in Figure 2(e), for Li-doped samples, a higher PF can be obtained in $\mathrm{Pb}_{0.99} \mathrm{Li}_{0.01} \mathrm{~S}$ in a broad temperature range, and the peak value can reach $11.5 \mu \mathrm{W} / \mathrm{cmK}^{2}$ at $450 \mathrm{~K}$. The peak $\mathrm{PF}$ for $\mathrm{Pb}_{0.99} \mathrm{Li}_{0.01} \mathrm{~S}$ is much higher than $\mathrm{Pb}_{0.99} \mathrm{Na}_{0.01} \mathrm{~S}$ which is ascribed to the lower $n_{\mathrm{H}}$, namely, adjusting carrier concentration to an optimized scope. Figures 3(c) and 3(d) show the carrier mobility and carrier concentration at room temperature which are calculated by the carrier effective mass of $\mathrm{PbS}\left(m^{*}=0.38 m_{0}\right)$ [25]. According to Rowe and Bhandari's study [37], the $S$ decreases and the $\sigma$ increases as the $n_{\mathrm{H}}$ increases and the PF maximizes at a suitable $n_{\mathrm{H}}$ for a semiconductor. Therefore, adjusting the $n_{\mathrm{H}}$ to a reasonable range is the key factor to obtain higher PF. Compared with $\mathrm{Pb}_{0.99} \mathrm{Na}_{0.01} \mathrm{~S}$, Li doping leads to a 


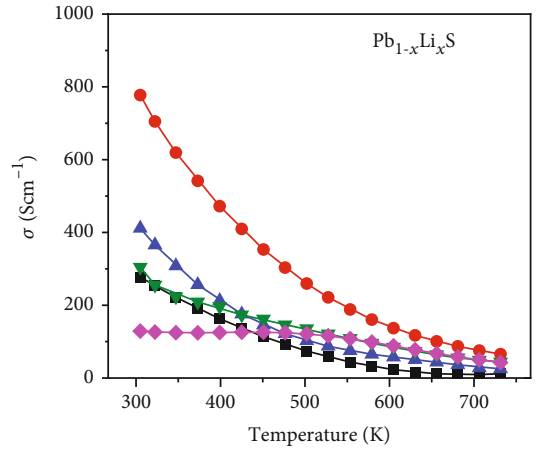

(a)

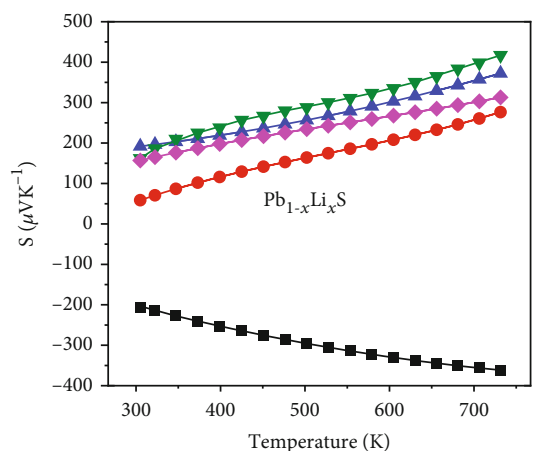

(c)

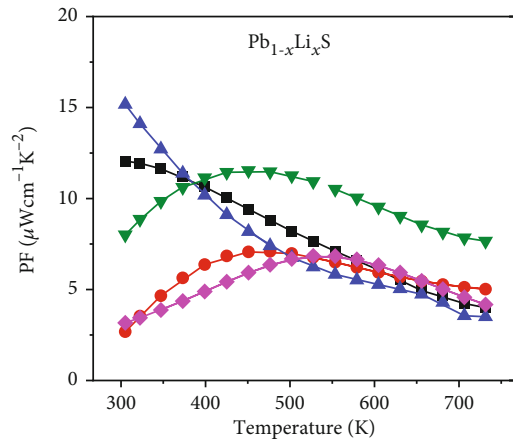

(e)

$$
\begin{aligned}
& \rightarrow x=0 \\
& \longrightarrow x=0.0050 \\
& \neg x=0.0075
\end{aligned}
$$

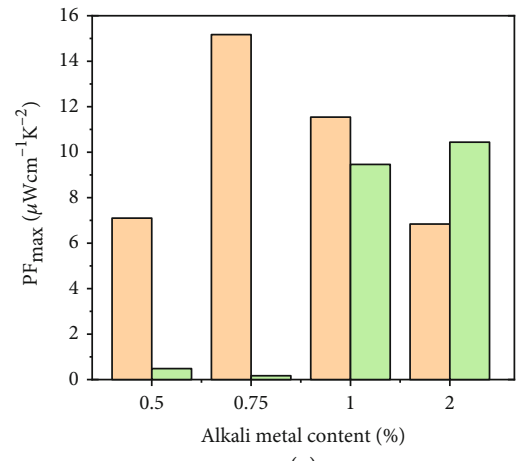

(g)

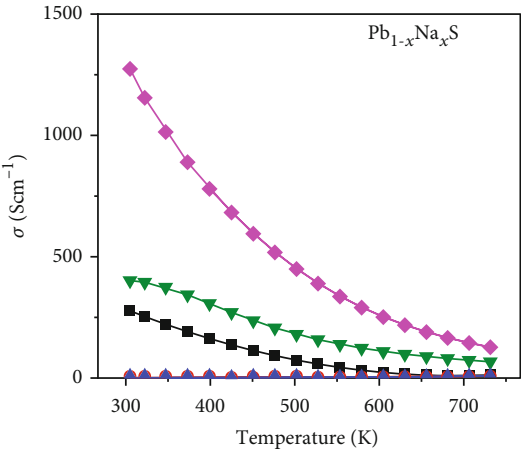

(b)

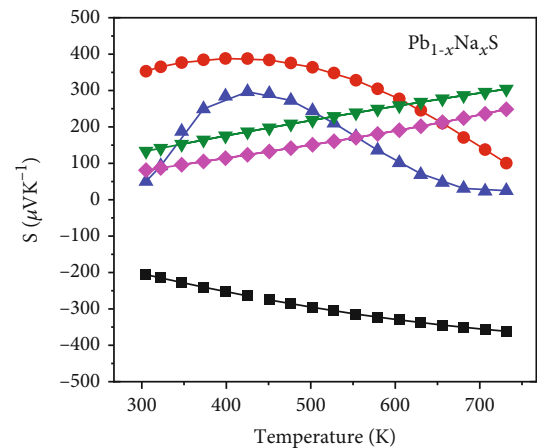

(d)

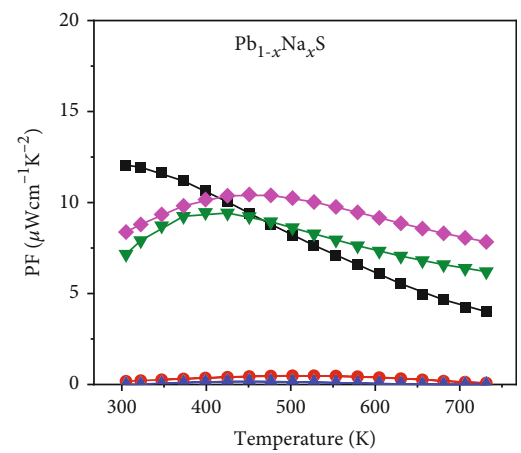

(f)

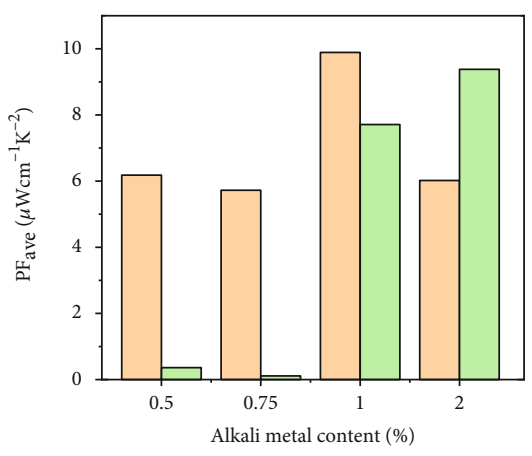

(h)

FIGURE 2: Temperature dependence of thermoelectric transport properties of $\mathrm{Pb}_{1-x} \mathrm{Li}_{x} \mathrm{~S}$ and $\mathrm{Pb}_{1-x} \mathrm{Na}_{x} \mathrm{~S}$ : (a, b) electrical conductivity, (c, d) Seebeck coefficient, (e, f) power factor (PF), (g) comparisons of maximum PF, and (h) averaged PF at 423-730 K. 


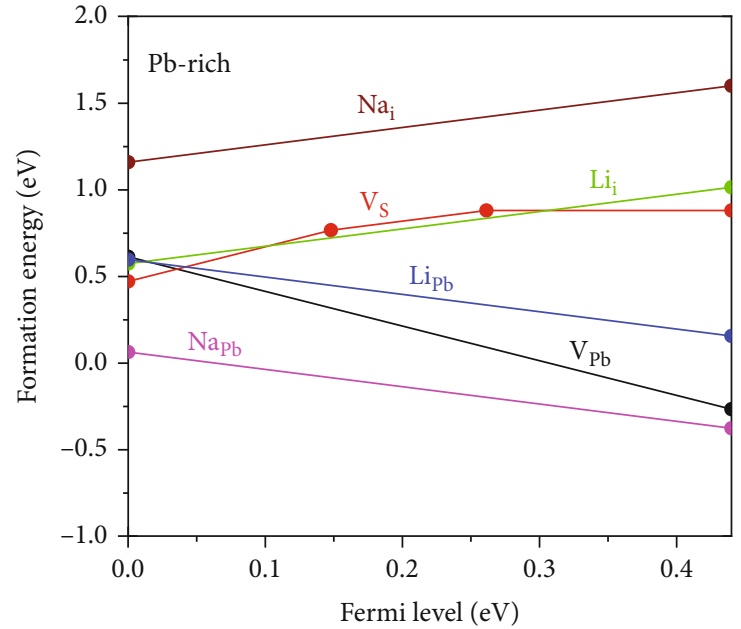

(a)

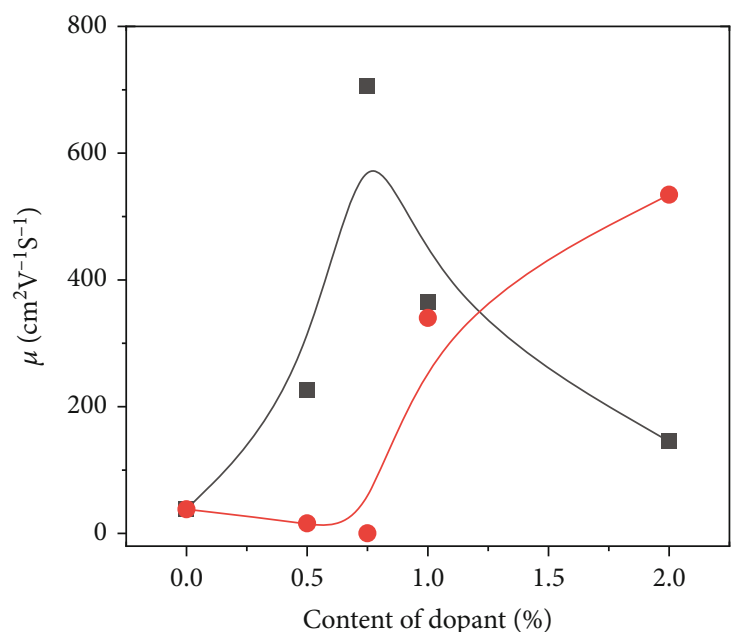

(c)

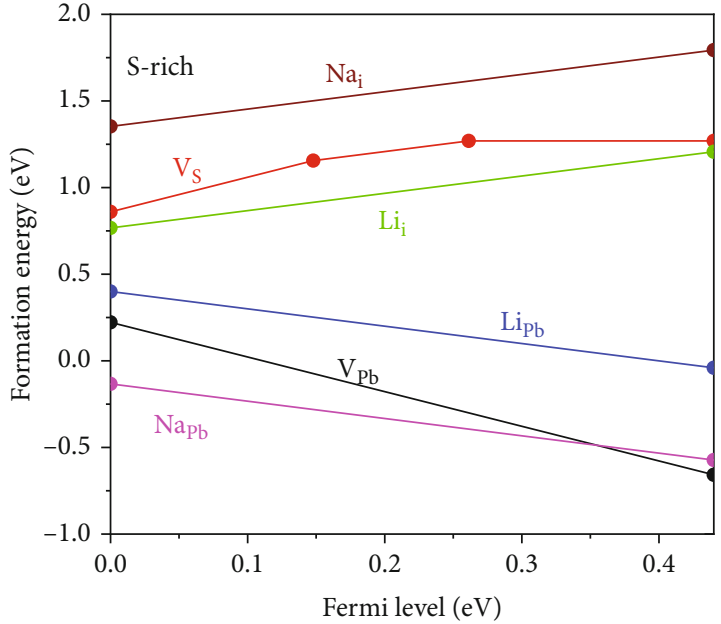

(b)

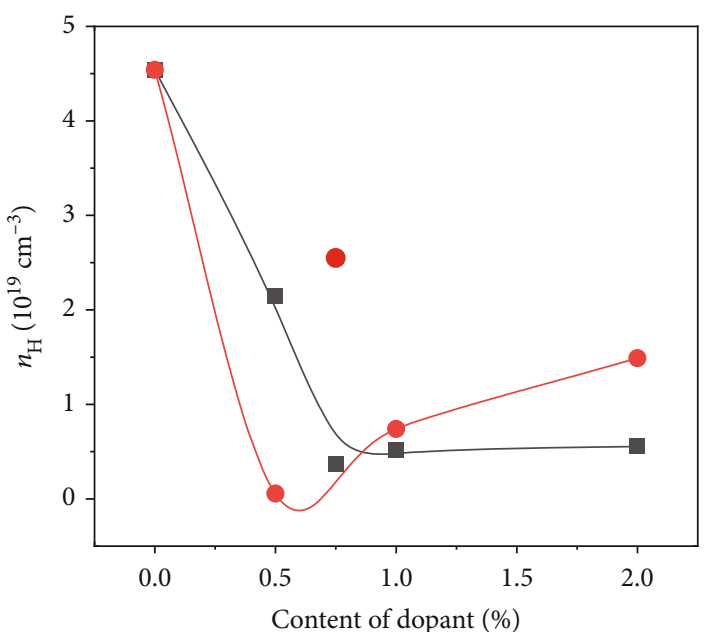

(d)

$$
\begin{aligned}
& -\mathrm{Pb}_{1-x} \mathrm{Li}_{x} \mathrm{~s} \\
& -\mathrm{Pb}_{1-x} \mathrm{Na}_{x} \mathrm{~s}
\end{aligned}
$$

Figure 3: The calculated formation energy of potential defect in PbS under (a) Pb-rich and (b) S-rich conditions. The Fermi level with respect to the valence band maximum (VBM) of PbS. (c, d) The carrier mobility and carrier concentration of $\mathrm{Pb}_{1-x} \mathrm{Li}_{x} \mathrm{~S}$ and $\mathrm{Pb}_{1-x} \mathrm{Na}_{x} \mathrm{~S}$ at room temperature.

relative lower $n_{\mathrm{H}}$ and higher PF. Figures $2(\mathrm{~g})$ and 2(h) show the maximum power factor $\left(\mathrm{PF}_{\max }\right)$ at $300-730 \mathrm{~K}$ and average power factor $\left(\mathrm{PF}_{\mathrm{ave}}\right)$ within $423-730 \mathrm{~K}$ of $p$-type $\mathrm{PbS}$ samples. The $\mathrm{PF}_{\text {ave }}$ is calculated by Equation (7) in which the $T_{\mathrm{h}}$ and $T_{\mathrm{c}}$ are the temperatures of hot and cold ends. The $\mathrm{PF}_{\mathrm{ave}}$ represents the overall capacity and level of electrical transports over a specified wide temperature range. The $\mathrm{PF}_{\max }$ and $\mathrm{PF}_{\text {ave }}$ of the $\mathrm{Pb}_{0.99} \mathrm{Li}_{0.01} \mathrm{~S}$ sample are 11.5 and $9.9 \mu \mathrm{W} / \mathrm{cmK}^{2}$, respectively, higher than those of $\mathrm{Pb}_{0.99} \mathrm{Na}_{0.01} \mathrm{~S}$ which are 9.5 and $7.7 \mu \mathrm{W} / \mathrm{cmK}^{2}$. The present results reveal that the different dopants can reach the $\mathrm{PF}_{\max }$ under their proper $n_{\mathrm{H}}$, which is strictly determined by the solid solubility of dopants in $\mathrm{PbS}$.

$$
\mathrm{PF}_{\mathrm{ave}}=\frac{1}{T_{\mathrm{h}}-T_{\mathrm{c}}} \int_{T_{\mathrm{c}}}^{T_{\mathrm{h}}} \mathrm{PF} d T
$$

Figures 4(a) and 4(b) depict the $\kappa_{\text {tot }}$ which decreases monotonically with the increase of temperature. The $\kappa_{\text {tot }}$ of $\mathrm{Pb}_{1-x} \mathrm{Li}_{x} \mathrm{~S}$ is lower than that in the undoped $\mathrm{PbS}$, which is different from the larger content of $\mathrm{Pb}_{1-x} \mathrm{Na}_{x} \mathrm{~S}$ since $\sigma$ is higher. The $C_{\mathrm{p}}$ of $\mathrm{Pb}_{0.99} \mathrm{Li}_{0.01} \mathrm{~S}$ and $\mathrm{Pb}_{0.99} \mathrm{Na}_{0.01} \mathrm{~S}$ is $0.2094 \mathrm{~J} / \mathrm{g} \cdot \mathrm{K}$ and $0.2092 \mathrm{~J} / \mathrm{g} \cdot \mathrm{K}$ at $730 \mathrm{~K}$, respectively. The $C_{\mathrm{p}}$ of Li-doped samples is similar to the $C_{\mathrm{p}}$ of $\mathrm{Na}$-doped samples at the same content and temperature. The $\kappa_{\text {tot }}$ includes lattice thermal conductivity and electronic thermal conductivity $\left(\kappa_{\text {tot }}=\kappa_{\text {lat }}+\kappa_{\text {ele }}\right)[22,25]$, where the relationship between $\kappa_{\text {ele }}$, $\sigma$, and Lorenz number $(L)$ described in Equation (8) indicates that the $\kappa_{\text {ele }}$ is proportional to $\sigma$ $[38,39]$.

$$
\kappa_{\text {ele }}=L \sigma T \text {. }
$$




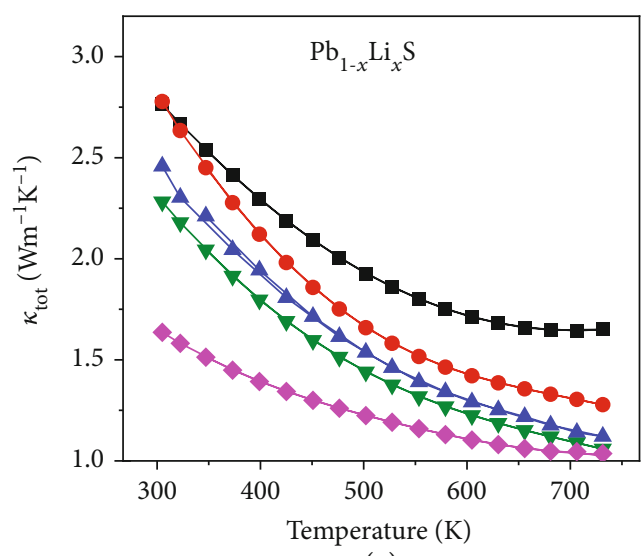

(a)

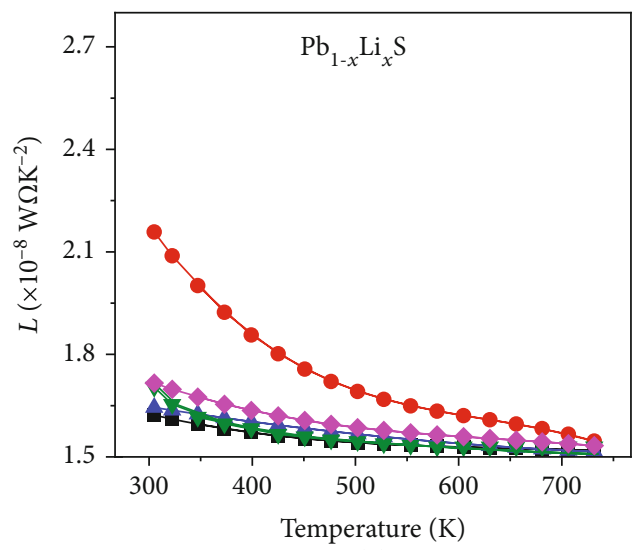

(c)

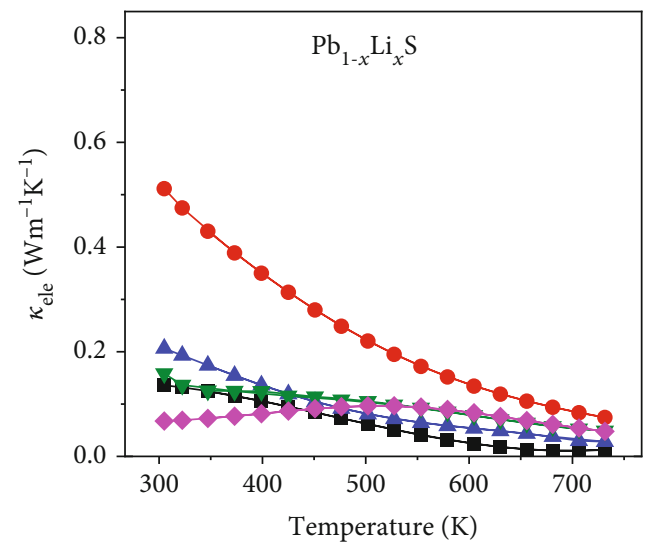

(e)

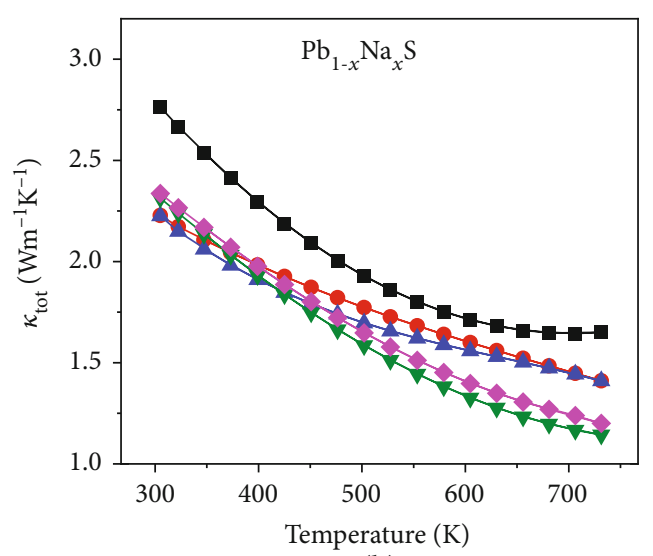

(b)

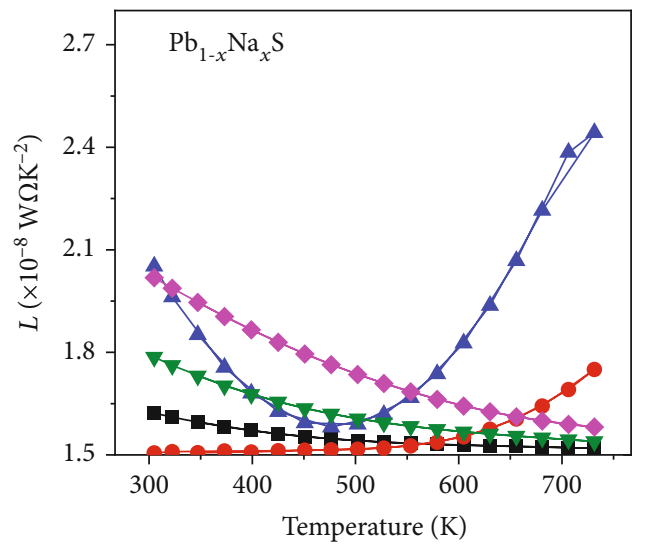

(d)

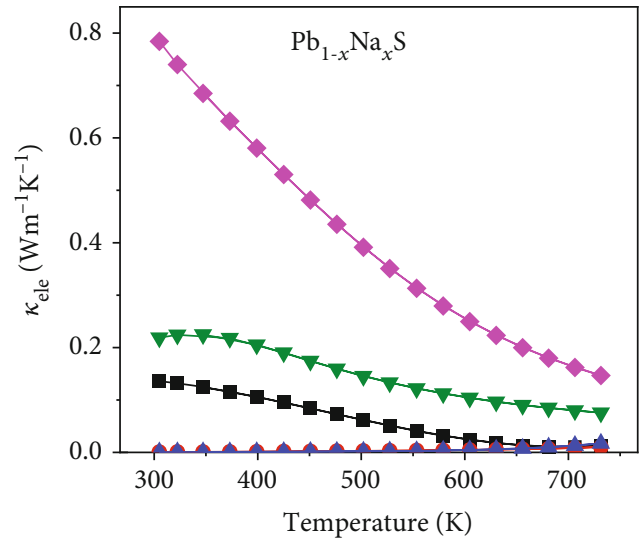

(f)

$$
\begin{array}{ll}
\rightarrow x=0 & \rightarrow-x=0.0100 \\
-x=0.0050 & \checkmark x=0.0200
\end{array}
$$

FiguRe 4: Temperature dependence of thermal transport properties of $\mathrm{Pb}_{1-x} \mathrm{Li}_{x} \mathrm{~S}$ and $\mathrm{Pb}_{1-x} \mathrm{Na}_{x} \mathrm{~S}:(\mathrm{a}, \mathrm{b})$ total thermal conductivity, (c, d) Lorenz number, and $(e, f)$ electronic thermal conductivity.

The Lorenz number was obtained through calculating the Seebeck coefficient and integral chemical potentials [40]. Figures 4(c) and 4(d) show the Lorenz number in all samples as function of temperature. Higher $L$ and $\sigma$ lead to the larger $\kappa_{\text {ele }}$ than those in undoped $\mathrm{PbS}$, as revealed through Figures $4(\mathrm{e})$ and 4(f). Thus, the reduction in $\kappa_{\text {tot }}$ is primarily caused by the decrease of $\kappa_{\text {lat }}$.
Figures 5(a) and 5(b) show that the $\kappa_{\text {lat }}$ of all doped samples is lower than that of the undoped sample. The point defect scattering presumably reduces the $\kappa_{\text {lat }}$ by $\mathrm{Li}$ and $\mathrm{Na}$ doping. Obviously, the $\kappa_{\text {lat }}$ decreases with the increasing dopant content. More importantly, Li and $\mathrm{Na}$ are both effective in reducing the $\kappa_{\text {lat }}$. To understand the phonon transports in $\mathrm{Li}-(\mathrm{Na})$ doped $\mathrm{PbS}$, we adopted the Callaway model to 


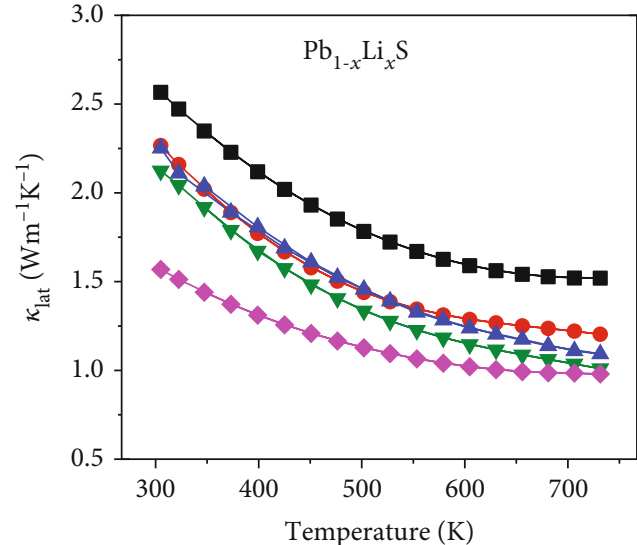

(a)

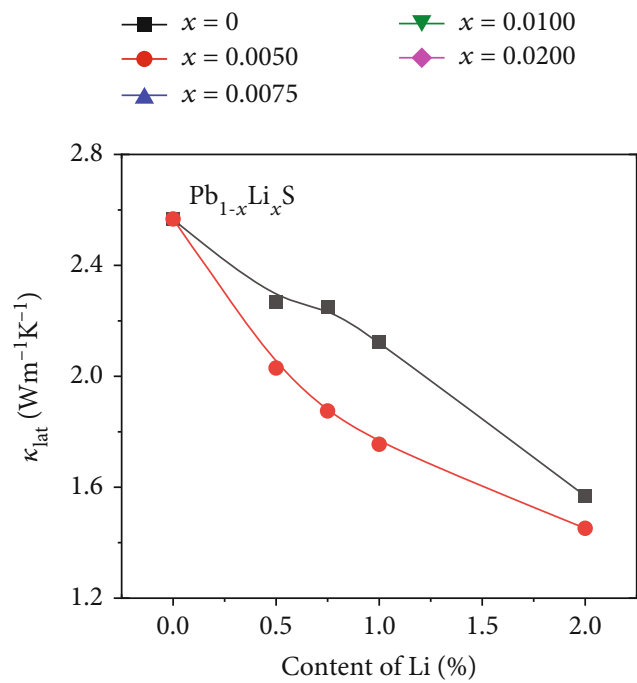

(c)

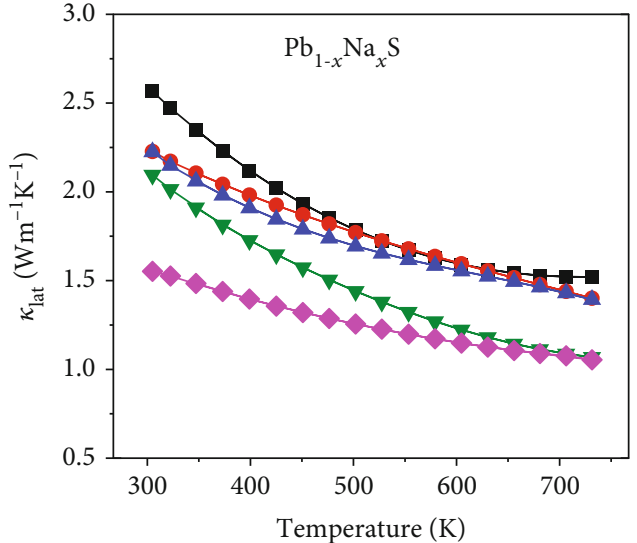

(b)

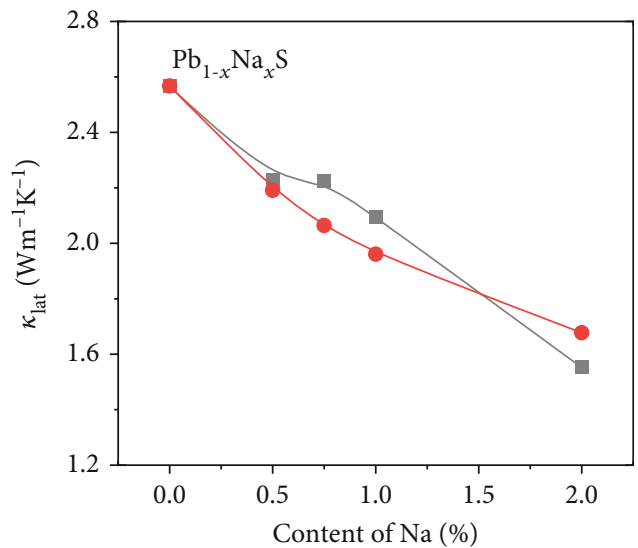

(d)

FIgure 5: Temperature dependence of thermal transport properties of $\mathrm{Pb}_{1-x} \mathrm{Li}_{x} \mathrm{~S}$ and $\mathrm{Pb}_{1-x} \mathrm{Na}_{x} \mathrm{~S}:(\mathrm{a}, \mathrm{b})$ lattice thermal conductivity and (c, d) comparisons of $\kappa_{\text {lat }}$ between experimental and calculated values.

evaluate point defect scattering caused by Li and Na doping $[28,41,42]$.

When the temperature is higher than the Debye temperature, the point defect is an intensive scattering center to reduce the $\kappa_{\text {lat }}$. According to the Callaway model [28, 42, 43 ], the ratio of the $\kappa_{\text {lat }}$ between the defect-containing material and host material can be written as

$$
\frac{\kappa_{\text {lat }}}{\kappa_{\text {lat,p }}}=\frac{\tan ^{-1} u}{u},
$$

in which $\kappa_{\text {lat }}$ and $\kappa_{\text {lat,p }}$ represent the lattice thermal conductivities in doped and parent materials, separately. The parameter $u$ is described using

$$
u=\left(\frac{\pi^{2} \theta_{\mathrm{D}} \Omega}{h v_{\mathrm{a}}^{2}} K_{L, p} \Gamma\right)^{1 / 2}
$$

in which $h, \Omega, v_{\mathrm{a}}$, and $\theta_{\mathrm{D}}$ express the Planck constant, average atom volume, average sound velocity, and Debye temperature, separately. The imperfection scaling parameter $(\Gamma)$ indicates that the phonon scattering intensity by atomic scale defects contains mass fluctuation $\Gamma_{\mathrm{M}}$ and strain field fluctuation $\Gamma_{\mathrm{S}}$. The phenomenological adjustable parameter $(\varepsilon)$ regulates the uncertainty of $\Gamma_{\mathrm{S}}$. The imperfection scaling parameter $\Gamma$ and the phenomenological adjustable parameter $\varepsilon$ are expressed by the following equations [42]:

$$
\begin{aligned}
& \Gamma=\Gamma_{\mathrm{M}}+\varepsilon \Gamma_{\mathrm{S}}, \\
& \varepsilon=\frac{2}{9}\left(\frac{6.4 \times \gamma\left(1+v_{\mathrm{p}}\right)}{\left(1-v_{\mathrm{p}}\right)}\right)^{2},
\end{aligned}
$$

where $v_{\mathrm{p}}$ displays the Poisson ratio, which is calculated using the longitudinal $\left(v_{1}\right)$ and transverse $\left(v_{\mathrm{s}}\right)$ acoustic velocities. The acoustic velocity of $\mathrm{PbS}$ was adopted in Poisson ratio 
and Grüneisen parameter $(\gamma)$ calculation by the following equations:

$$
\begin{gathered}
v_{\mathrm{p}}=\frac{1-2\left(\nu_{\mathrm{s}} / \nu_{1}\right)^{2}}{2-2\left(v_{\mathrm{s}} / \nu_{1}\right)^{2}}, \\
\gamma=\frac{2}{3}\left(\frac{1+\nu_{\mathrm{p}}}{2-3 v_{\mathrm{p}}}\right) .
\end{gathered}
$$

When $\mathrm{Pb}$ sites are replaced by $\mathrm{Li}(\mathrm{Na})$, no change happens on the position of $\mathrm{S}, \Gamma_{\mathrm{S}}=0$, which is defined by $[44,45]$

$$
\begin{aligned}
\Gamma_{\mathrm{Pb}_{1-x} Q_{x} \mathrm{~S}} & =\frac{1}{2}\left(\frac{M_{((\mathrm{Pb}, \mathrm{Q}))}}{\bar{M}}\right)^{2} \Gamma_{(\mathrm{Pb}, Q)}, \\
\Gamma_{(\mathrm{Pb}, Q)} & =\Gamma_{\mathrm{M},(\mathrm{Pb}, \mathrm{Q})}+\varepsilon \Gamma_{\mathrm{S},(\mathrm{Pb}, \mathrm{Q})}, \\
\Gamma_{\mathrm{M},(\mathrm{Pb}, \mathrm{Q})} & =x(1-x)\left(\frac{\Delta M}{M_{(\mathrm{Pb}, \mathrm{Q})}}\right)^{2},
\end{aligned}
$$

where $\Delta M=M_{\mathrm{Pb}}-M_{\mathrm{Q}}$, and $M_{(\mathrm{Pb}, \mathrm{Q})}=(1-x) M_{\mathrm{Pb}}+x M_{\mathrm{Q}}$.

$$
\Gamma_{\mathrm{S},(\mathrm{Pb}, \mathrm{Q})}=x(1-x)\left(\frac{\Delta r}{r_{(\mathrm{Pb}, Q)}}\right)^{2}
$$

where $\Delta r=r_{P b}-r_{Q}$, and $r_{(\mathrm{Pb}, Q)}=(1-x) r_{\mathrm{Pb}}+x r_{\mathrm{Q}}$.

Then,

$\Gamma_{\mathrm{Pb}_{1-x} Q_{x} S}=\frac{1}{2}\left(\frac{M_{((\mathrm{Pb}, Q))}}{\bar{M}}\right)^{2} x(1-x)\left[\left(\frac{\Delta M}{M_{(\mathrm{Pb}, Q)}}\right)^{2}+\varepsilon\left(\frac{\Delta r}{r_{(\mathrm{Pb}, Q)}}\right)^{2}\right]$.

The calculated mass fluctuations $\Gamma_{\mathrm{M},(\mathrm{Pb}, \mathrm{Q})}$ and strain field fluctuations $\Gamma_{\mathrm{S},(\mathrm{Pb}, \mathrm{Q})}$ have been given by Table 1 . The higher deviations in atomic radius and mass between $\mathrm{Pb}$ and $\mathrm{Li}$ lead to larger $\Gamma_{(\mathrm{Pb}, \mathrm{Li})}$ than $\Gamma_{(\mathrm{Pb}, \mathrm{Na})}$, indicating more effective decreasing of $\kappa_{\text {lat }}$ by Li doping. In Figures 5(c) and 5(d), the calculated results based on the Callaway model exhibit the same trend with the experimental data. The huge deviation may result from the formation of nanostructure even though in moderate doping concentration. This phenomenon confirms that $\mathrm{Li}$ and $\mathrm{Na}$ could both play effective roles in suppressing $\kappa_{\text {lat }}$.

The temperature-dependent ZT of PbS doped by Li and $\mathrm{Na}$ are presented in Figures 6(a) and 6(b). $\mathrm{Pb}_{1-x} \mathrm{Li}_{x} \mathrm{~S}$ samples exhibit larger $\mathrm{ZT}$ than $\mathrm{Pb}_{1-x} \mathrm{Na}_{x} \mathrm{~S}$ samples. The maximum $\mathrm{ZT}$ $\left(\mathrm{ZT}_{\text {max }}\right)$ in $\mathrm{Pb}_{0.99} \mathrm{Li}_{0.01} \mathrm{~S}$ attained $\sim 0.5$ when $T=730 \mathrm{~K}$, which is higher than that in $\mathrm{Pb}_{0.99} \mathrm{Na}_{0.01} \mathrm{~S}$. The better thermoelectric performance of Li-doped samples is mainly due to the higher PF which results from the obtained proper $n_{\mathrm{H}}$ range and the slightly lower $\kappa_{\text {tot }}$ from a more effective point defect scattering.

The variation trends of maximum $\mathrm{ZT}\left(\mathrm{ZT}_{\max }\right)$ and average $\mathrm{ZT}\left(\mathrm{ZT}_{\mathrm{ave}}\right)$, calculated by Equation (16), are consistent with $\mathrm{PF}_{\max }$ and $\mathrm{PF}_{\mathrm{ave}}$, as displayed in Figures 6(c) and 6(d).
TABLE 1: Calculated imperfection scaling parameters and $\kappa_{\text {lat }}$ $(\mathrm{W} / \mathrm{mK})$ of $\mathrm{Li}$ - and $\mathrm{Na}$-doped $\mathrm{PbS}$ based on the Callaway model.

\begin{tabular}{lcccc}
\hline Samples & $\Gamma_{\mathrm{M},(\mathrm{Pb}, \mathrm{Q})}$ & $\Gamma_{\mathrm{S},(\mathrm{Pb}, \mathrm{Q})}$ & $\Gamma_{(\mathrm{Pb}, \mathrm{Q})}$ & $\kappa_{\text {lat }}$ \\
\hline $\mathrm{Pb}_{0.995} \mathrm{Li}_{0.0050} \mathrm{~S}$ & 0.004693 & 0.000072 & 0.010254 & 2.03 \\
$\mathrm{~Pb}_{0.995} \mathrm{Li}_{0.0075} \mathrm{~S}$ & 0.007055 & 0.000107 & 0.015382 & 1.87 \\
$\mathrm{~Pb}_{0.99} \mathrm{Li}_{0.0100} \mathrm{~S}$ & 0.009429 & 0.000143 & 0.020510 & 1.75 \\
$\mathrm{~Pb}_{0.98} \mathrm{Li}_{0.0200} \mathrm{~S}$ & 0.019038 & 0.000284 & 0.041028 & 1.45 \\
$\mathrm{~Pb}_{0.995} \mathrm{Na}_{0.0050} \mathrm{~S}$ & 0.003967 & 0.000042 & 0.007189 & 2.19 \\
$\mathrm{~Pb}_{0.995} \mathrm{Na}_{0.0075} \mathrm{~S}$ & 0.005962 & 0.000062 & 0.010780 & 2.06 \\
$\mathrm{~Pb}_{0.99} \mathrm{Na}_{0.0100} \mathrm{~S}$ & 0.007965 & 0.000083 & 0.014370 & 1.96 \\
$\mathrm{~Pb}_{0.98} \mathrm{Na}_{0.0200} \mathrm{~S}$ & 0.016056 & 0.000163 & 0.028714 & 1.68 \\
\hline
\end{tabular}

The $\mathrm{ZT}_{\max }$ from room temperature to $730 \mathrm{~K}$ and $\mathrm{ZT}_{\text {ave }}$ within $423-730 \mathrm{~K}$ are 0.5 and 0.4 in $\mathrm{Pb}_{0.99} \mathrm{Li}_{0.01} \mathrm{~S}$, which is much higher than $\mathrm{Pb}_{0.99} \mathrm{Na}_{0.01} \mathrm{~S}$ (0.4 and 0.3 ). The quality factor $B$ is a parameter for estimating the optimal thermoelectric properties of a specific material according to the effective mass model, and the quality factor $B$ is obtained by Equation (16). The weighted mobility $\mu_{\mathrm{w}}$ is calculated by the electrical conductivity and Seebeck coefficient according to Equation (17) [46, 47].

$$
B=9 \frac{\mu_{\mathrm{W}}}{\kappa_{\text {lat }}}\left(\frac{T}{300}\right)^{5 / 2}
$$

$$
\mu_{\mathrm{W}}=\frac{3 \sigma}{8 \pi e F_{0}(\eta)}\left(\frac{h^{2}}{2 m_{e} k_{\mathrm{B}} T}\right)^{3 / 2}
$$

in which $m_{e}$ and $e$ are unit mass of free electron and the electron charge, respectively. $F_{n}(\eta)$ represents the Fermi integral with $n=0$ and is calculated by the following equations.

$$
\begin{aligned}
F_{n}(\eta) & =\int_{0}^{\infty} \frac{x^{n}}{1+e^{x-\eta}} d x, \\
S & = \pm \frac{k_{\mathrm{B}}}{e}\left\{\frac{(r+5 / 2) F_{r+3 / 2}(\eta)}{(r+3 / 2) F_{r+1 / 2}(\eta)}-\eta\right\},
\end{aligned}
$$

in which $r$ shows the scattering factor and equals $-1 / 2$ here and $\eta$ is the reduced chemical potential [46].

The calculated quality factors of $\mathrm{Pb}_{0.99} \mathrm{Li}_{0.01} \mathrm{~S}$ and $\mathrm{Pb}_{0.99} \mathrm{Na}_{0.01} \mathrm{~S}$ at $730 \mathrm{~K}$ are 0.4 and 0.2 , respectively. The quality factor of $\mathrm{Pb}_{0.99} \mathrm{Li}_{0.01} \mathrm{~S}$ is about twice higher than that of $\mathrm{Pb}_{0.99} \mathrm{Na}_{0.01} \mathrm{~S}$, so the $\mathrm{ZT}$ of $\mathrm{Pb}_{0.99} \mathrm{Li}_{0.01} \mathrm{~S}$ is higher, which is caused by the enhanced PF by adjusting $n_{\mathrm{H}}$ in a reasonable range. The thermoelectric conversion efficiencies are calculated by Equation (20) [28]:

$$
\begin{aligned}
\mathrm{ZT}_{\mathrm{ave}} & =\frac{1}{T_{\mathrm{h}}-T_{\mathrm{c}}} \int_{T_{\mathrm{C}}}^{T_{\mathrm{h}}} \mathrm{ZT} d T, \\
\eta & =\frac{T_{\mathrm{h}}-T_{\mathrm{c}}}{T_{\mathrm{h}}} \frac{\sqrt{1+\mathrm{ZT}_{\mathrm{ave}}}-1}{\sqrt{1+\mathrm{ZT}_{\mathrm{ave}}}+\left(T_{\mathrm{c}} / T_{\mathrm{h}}\right)},
\end{aligned}
$$




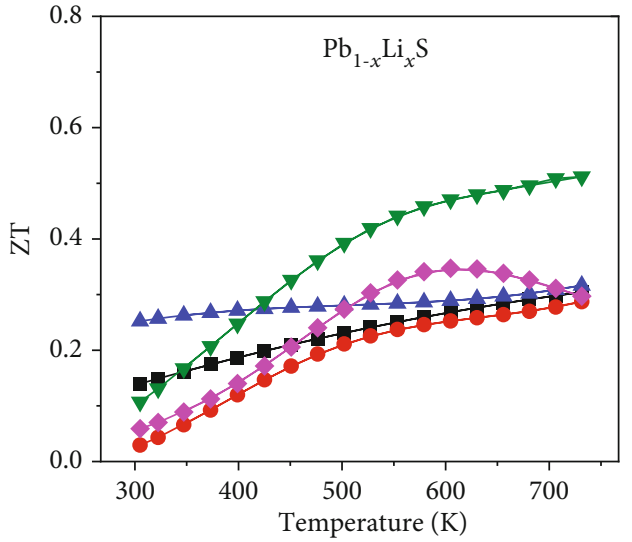

(a)

$$
\begin{aligned}
& \rightarrow x=0 \quad \nabla-x=0.0100 \\
& \longrightarrow x=0.0050 \\
& -\mathbb{x}=0.0075
\end{aligned}
$$

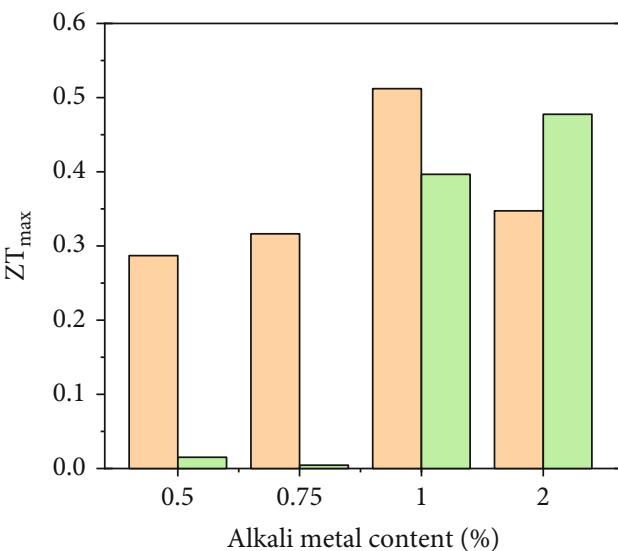

(c)

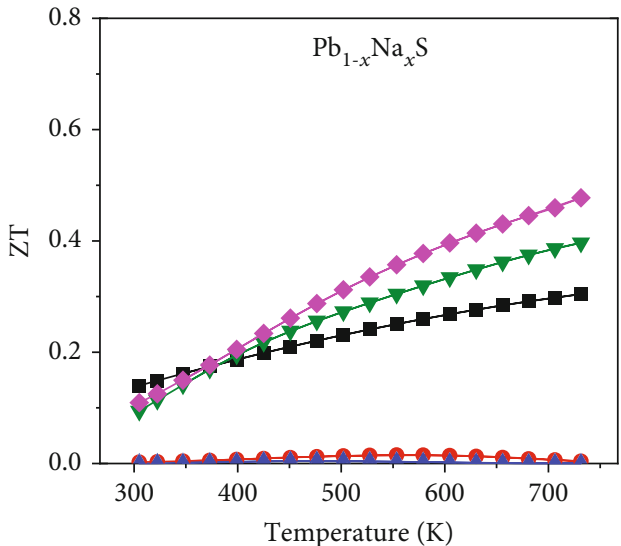

(b)

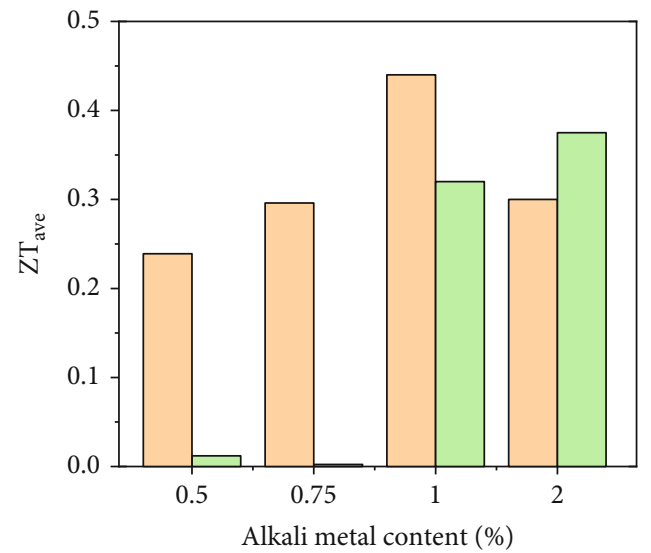

(d)

$\mathrm{Li}$

FIgure 6: Temperature dependence of $\mathrm{ZT}$ of (a) $\mathrm{Pb}_{1-x} \mathrm{Li}_{x} \mathrm{~S}$ and (b) $\mathrm{Pb}_{1-x} \mathrm{Na}_{x} \mathrm{~S}$ and comparisons of (c) maximum $\mathrm{ZT}$ and (d) averaged ZT at $423-730 \mathrm{~K}$.

in which $T_{\mathrm{h}}$ and $T_{\mathrm{c}}$ represent the temperature in hot and cold end, respectively. The maximum calculated thermoelectric conversion efficiency based on single leg is $\sim 4.8 \%$ in $\mathrm{Pb}_{0.99} \mathrm{Li}_{0.01} \mathrm{~S}$ which is higher than $\mathrm{Pb}_{0.99} \mathrm{Na}_{0.01} \mathrm{~S}(\sim 3.4 \%)$ when $T_{\mathrm{h}}=730 \mathrm{~K}$ and $T_{\mathrm{c}}=423 \mathrm{~K}$, indicating $\mathrm{Li}$ is a valid dopant to regulate the thermoelectric performance through tuning $n_{\mathrm{H}}$.

\section{Conclusion}

This work indicates that $\mathrm{Li}$ doping is more effective than $\mathrm{Na}$ doping in thermoelectric performance optimization in $\mathrm{PbS}$. The boosted thermoelectric performance of Li-doped $\mathrm{PbS}$ is completed by enhancing the PF through regulating $n_{\mathrm{H}}$ in a reasonable range. The $\mathrm{PF}_{\max }$ and $\mathrm{PF}_{\text {ave }}$ between 423 and $730 \mathrm{~K}$ of $\mathrm{Pb}_{0.99} \mathrm{Li}_{0.01} \mathrm{~S}$ reached $\sim 11.5$ and $\sim 9.9 \mu \mathrm{W} / \mathrm{cmK}^{2}$, which are much better compared with $\sim 9.5$ and $\sim 7.7 \mu \mathrm{W} / \mathrm{cmK}^{2}$ of $\mathrm{Pb}_{0.99} \mathrm{Na}_{0.01} \mathrm{~S} . \mathrm{Pb}_{1-x} \mathrm{Li}_{x} \mathrm{~S}$ samples possess slightly smaller $\kappa_{\text {lat }}$ than that of $\mathrm{Pb}_{1-x} \mathrm{Na}_{x} \mathrm{~S}$ because of larger mass and strain field fluctuations. At last, higher $Z \mathrm{~T}_{\max }$ $\sim 0.5$ at $730 \mathrm{~K}$ and $\mathrm{ZT}_{\text {ave }} \sim 0.4$ at $423 \mathrm{~K}-730 \mathrm{~K}$ can be obtained in $\mathrm{Pb}_{0.99} \mathrm{Li}_{0.01} \mathrm{~S}$. The calculated thermoelectric conversion efficiency $\sim 4.8 \%$ is achieved in $\mathrm{Pb}_{0.99} \mathrm{Li}_{0.01} \mathrm{~S}$ with $T_{\mathrm{h}}=730 \mathrm{~K}$ and $T_{\mathrm{c}}=423 \mathrm{~K}$. In the future, the ZT for Li-doped PbS can also be raised through nanostructuring, manipulating band structures, and other approaches.

\section{Conflicts of Interest}

The authors declare no competing financial interests.

\section{Acknowledgments}

We acknowledge the support on this topic from the National Natural Science Foundation of China (51772012 and 51671015), the National Key Research and Development 
Program of China (2018YFA0702100 and 2018YFB0703600), Beijing Natural Science Foundation (JQ18004), and 111 Project (B17002). L.D.Z. acknowledges the support of the National Science Fund for Distinguished Young Scholars (51925101). Z.H. thanks the financial support from the Academic Excellence Foundation of BUAA for PhD Students. D.W. thanks the financial support from the National Postdoctoral Program for Innovative Talents (BX20200028) and the support from high-performance computing (HPC) resources at Beihang University. J.W. and G.W. acknowledges the support of the High Performance Computing Center of Henan Normal University. Z.H. thanks the support from China Postdoctoral Science Foundation Grant (2019M650429).

\section{References}

[1] L. E. Bell, "Cooling, heating, generating power, and recovering waste heat with thermoelectric systems," Science, vol. 321, no. 5895, pp. 1457-1461, 2008.

[2] G. Tan, L.-D. Zhao, and M. G. Kanatzidis, "Rationally designing high-performance bulk thermoelectric materials," Chemical Reviews, vol. 116, no. 19, pp. 12123-12149, 2016.

[3] Z. G. Chen, X. Shi, L. D. Zhao, and J. Zou, "High-performance SnSe thermoelectric materials: progress and future challenge," Progress in Materials Science, vol. 97, pp. 283-346, 2018.

[4] Y. Xiao, C. Chang, Y. Pei et al., "Origin of low thermal conductivity in SnSe," Physical Review B, vol. 94, no. 12, article 125203, 2016.

[5] G. Tang, W. Wei, J. Zhang et al., "Realizing high figure of merit in phase-separated polycrystalline $\mathrm{Sn}_{1-\mathrm{x}} \mathrm{Pb}_{\mathrm{x}} \mathrm{Se}$," Journal of the American Chemical Society, vol. 138, no. 41, pp. 1364713654, 2016

[6] Y. Liu, L.-D. Zhao, Y. Zhu et al., "Synergistically optimizing electrical and thermal transport properties of $\mathrm{BiCuSeO}$ via a dual-doping approach," Advanced Energy Materials, vol. 6, no. 9, article 1502423, 2016.

[7] L.-D. Zhao, X. Zhang, H. Wu et al., "Enhanced thermoelectric properties in the counter-doped SnTe system with strained endotaxial SrTe," Journal of the American Chemical Society, vol. 138, no. 7, pp. 2366-2373, 2016.

[8] Y. Xiao, H. Wu, W. Li et al., "Remarkable roles of Cu to synergistically optimize phonon and carrier transport in n-type

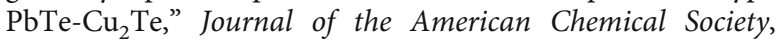
vol. 139, no. 51, pp. 18732-18738, 2017.

[9] B. C. Qin, Y. Xiao, Y. M. Zhou, and L. D. Zhao, "Thermoelectric transport properties of $\mathrm{Pb}-\mathrm{Sn}$-Te-Se system," Rare Metals, vol. 37, no. 4, pp. 343-350, 2018.

[10] C. Chang, M. Wu, D. He et al., " $3 \mathrm{D}$ charge and $2 \mathrm{D}$ phonon transports leading to high out-of-planeZTin n-type SnSe crystals," Science, vol. 360, no. 6390, pp. 778-783, 2018.

[11] Y. L. Pei and Y. Liu, "Electrical and thermal transport properties of Pb-based chalcogenides: PbTe, PbSe, and PbS," Journal of Alloys and Compounds, vol. 514, pp. 40-44, 2012.

[12] Y. Xiao, H. Wu, J. Cui et al., "Realizing high performance n-type $\mathrm{PbTe}$ by synergistically optimizing effective mass and carrier mobility and suppressing bipolar thermal conductivity," Energy \& Environmental Science, vol. 11, no. 9, pp. 2486-2495, 2018.

[13] Y. Xiao, H. Wu, D. Wang et al., "Amphoteric indium enables carrier engineering to enhance the power factor and thermoelectric performance inn-Type AgnPb100InnTe100 +2n(LIST)," Advanced Energy Materials, vol. 9, no. 17, article 1900414, 2019.

[14] L.-D. Zhao, H. J. Wu, S. Q. Hao et al., "All-scale hierarchical thermoelectrics: MgTe in PbTe facilitates valence band convergence and suppresses bipolar thermal transport for high performance," Energy \& Environmental Science, vol. 6, no. 11, pp. 3346-3355, 2013.

[15] K. Hsu, S. Loo, F. Guo et al., "Cubic $\mathrm{AgPb}_{\mathrm{m}} \mathrm{SbTe}_{2+\mathrm{m}}$ : bulk thermoelectric materials with high figure of merit," Science, vol. 303, no. 5659, pp. 818-821, 2004.

[16] K. Biswas, J. He, I. D. Blum et al., "High-performance bulk thermoelectrics with all-scale hierarchical architectures," Nature, vol. 489, no. 7416, pp. 414-418, 2012.

[17] J. P. Heremans, V. Jovovic, E. S. Toberer et al., "Enhancement of thermoelectric efficiency in PbTe by distortion of the electronic density of states," Science, vol. 321, no. 5888, pp. 554557,2008

[18] G. Tan, F. Shi, S. Hao et al., "Codoping in SnTe: enhancement of thermoelectric performance through synergy of resonance levels and band convergence," Journal of the American Chemical Society, vol. 137, no. 15, pp. 5100-5112, 2015.

[19] M. Zhao, C. Chang, Y. Xiao, R. Gu, J. He, and L. D. Zhao, "Investigations on distinct thermoelectric transport behaviors of $\mathrm{Cu}$ in n-type PbS," Journal of Alloys and Compounds, vol. 781, pp. 820-830, 2019.

[20] Y. Wang, J. Wen, Z. Fan et al., "Energy-filtering-induced high power factor in PbS-nanoparticles-embedded $\mathrm{TiS}_{2}$," AIP Advances, vol. 5, no. 4, article 047126, 2015.

[21] C. Chang, Y. Xiao, X. Zhang et al., "High performance thermoelectrics from earth-abundant materials: enhanced figure of merit in $\mathrm{PbS}$ through nanostructuring grain size," Journal of Alloys and Compounds, vol. 664, pp. 411-416, 2016.

[22] X. Qian, L. Zheng, Y. Xiao, C. Chang, and L. D. Zhao, "Enhancing thermoelectric performance of n-type PbSe via additional meso-scale phonon scattering," Inorganic Chemistry Frontiers, vol. 4, no. 4, pp. 719-726, 2017.

[23] M. Cutler, J. F. Leavy, and R. L. Fitzpatrick, "Electronic transport in semimetallic cerium sulfide," Physical Review, vol. 133, no. 4A, pp. A1143-A1152, 1964.

[24] B. Poudel, Q. Hao, Y. Ma et al., "High-thermoelectric performance of nanostructured bismuth antimony telluride bulk alloys," Science, vol. 320, no. 5876, pp. 634-638, 2008.

[25] L.-D. Zhao, J. He, S. Hao et al., "Raising the thermoelectric performance of $\mathrm{p}$-type $\mathrm{PbS}$ with endotaxial nanostructuring and valence-band offset engineering using $\mathrm{CdS}$ and $\mathrm{ZnS}$," Journal of the American Chemical Society, vol. 134, no. 39, pp. 16327-16336, 2012.

[26] L.-D. Zhao, J. He, C. I. Wu et al., "Thermoelectrics with earth abundant elements: high performance p-type $\mathrm{PbS}$ nanostructured with SrS and CaS," Journal of the American Chemical Society, vol. 134, no. 18, pp. 7902-7912, 2012.

[27] S. Johnsen, J. He, J. Androulakis et al., "Nanostructures boost the thermoelectric performance of PbS," Journal of the American Chemical Society, vol. 133, no. 10, pp. 3460-3470, 2011.

[28] B. Qin, D. Wang, W. He et al., "Realizing high thermoelectric performance in p-type SnSe through crystal structure modification," Journal of the American Chemical Society, vol. 141, no. 2, pp. 1141-1149, 2019.

[29] P. E. Blöchl, "Projector augmented-wave method," Physical Review B, vol. 50, no. 24, pp. 17953-17979, 1994. 
[30] G. Kresse and D. Joubert, "From ultrasoft pseudopotentials to the projector augmented-wave method," Physical Review B, vol. 59, no. 3, pp. 1758-1775, 1999.

[31] G. Kresse and J. Furthmüller, "Efficient iterative schemes for ab initio total-energy calculations using a plane-wave basis set," Physical Review B, vol. 54, no. 16, pp. 11169-11186, 1996.

[32] Y. Zhou, W. Li, M. Wu et al., "Influence of defects on the thermoelectricity in SnSe: a comprehensive theoretical study," Physical Review B, vol. 97, no. 24, article 245202, 2018.

[33] S. H. Wei, "Overcoming the doping bottleneck in semiconductors," Computational Materials Science, vol. 30, no. 3-4, pp. 337-348, 2004.

[34] Z.-K. Yuan, S. Chen, Y. Xie et al., "Na-diffusion enhanced p-type conductivity in $\mathrm{Cu}(\mathrm{In}, \mathrm{Ga}) \mathrm{Se}_{2}$ : a new mechanism for efficient doping in semiconductors," Advanced Energy Materials, vol. 6, no. 24, article 1601191, 2016.

[35] C. Xia, Y. Jia, and Q. Zhang, "First-principles electronic structure and formation energies of group V and VII impurities in the $\alpha-\mathrm{Fe}_{2} \mathrm{O}_{3}$ alloys," Journal of Applied Physics, vol. 116, no. 11, article 113706, 2014.

[36] S. B. Zhang, S.-H. Wei, and A. Zunger, "Overcoming doping bottlenecks in semiconductors and wide-gap materials," Physica B-Condensed Matter, vol. 273-274, pp. 976-980, 1999.

[37] G. A. Moore, "Modern thermoelectrics," Electronics and Power, vol. 30, no. 9, p. 733, 1984.

[38] H. Mori, H. Usui, M. Ochi, and K. Kuroki, “Temperature- and doping-dependent roles of valleys in the thermoelectric performance of SnSe: a first-principles study," Physical Review B, vol. 96, no. 8, p. 10, 2017.

[39] Y. Pei, A. D. LaLonde, N. A. Heinz et al., "Stabilizing the optimal carrier concentration for high thermoelectric efficiency," Advanced Materials, vol. 23, no. 47, pp. 5674-5678, 2011.

[40] L.-D. Zhao, V. P. Dravid, and M. G. Kanatzidis, “The panoscopic approach to high performance thermoelectrics," Energy \& Environmental Science, vol. 7, no. 1, pp. 251-268, 2014.

[41] K. Ahn, K. Biswas, J. He, I. Chung, V. Dravid, and M. G. Kanatzidis, "Enhanced thermoelectric properties of p-type nanostructured PbTe-MTe (M = Cd, Hg) materials," Energy \& Environmental Science, vol. 6, no. 5, pp. 1529-1537, 2013.

[42] M. Zhao, C. Chang, Y. Xiao, and L. D. Zhao, "High performance of n-type $(\mathrm{PbS})_{1-\mathrm{x}-\mathrm{y}}(\mathrm{PbSe})_{\mathrm{x}}(\mathrm{PbTe})_{\mathrm{y}}$ thermoelectric materials," Journal of Alloys and Compounds, vol. 744, pp. 769-777, 2018.

[43] C. L. Wan, W. Pan, Q. Xu et al., "Effect of point defects on the thermal transport properties of $\left(\mathrm{La}_{\mathrm{x}} \mathrm{Gd}_{1-\mathrm{x}}\right)_{2} \mathrm{Zr}_{2} \mathrm{O}_{7}$ : experiment and theoretical model," Physical Review B, vol. 74, no. 14, article 144109, 2006.

[44] Y.-L. Pei, J. He, J. F. Li et al., "High thermoelectric performance of oxyselenides: intrinsically low thermal conductivity of Cadoped BiCuSeO," NPG Asia Materials, vol. 5, no. 5, article e47, 2013.

[45] G. Tan, F. Shi, H. Sun et al., "SnTe-AgBiTe 2 as an efficient thermoelectric material with low thermal conductivity," Journal of Materials Chemistry A, vol. 2, no. 48, pp. 20849-20854, 2014.

[46] Y. Xiao, D. Wang, Y. Zhang et al., "Band sharpening and band alignment enable high quality factor to enhance thermoelectric performance in n-type PbS," Journal of the American Chemical Society, vol. 142, no. 8, pp. 4051-4060, 2020.

[47] B. Qin, W. He, and L.-D. Zhao, "Estimation of the potential performance in p-type SnSe crystals through evaluating weighted mobility and effective mass," Journal of Materiomics, vol. 6, no. 4, pp. 671-676, 2020. 